\title{
Some Technique-Dependent Patterns of Collateral Flow during Cerebral Angiography*
}

\author{
J.F. Seeger, T. O. Gabrielsen, and R.E. Latchaw \\ Department of Radiology, Univorsity of Michigan Medical Center, Ann Arbor, Mich. 48104, USA \\ Received: January 14, 1974
}

Summary. During selective transfemoral catheter cerebral angiography, anastomoses between external carotid branches and the vertebral artery, between the vertebral and deep or ascending cervical arteries, and between the middle meningeal and ophthalmic arteries can be demonstrated fairly frequently in patients with no known vascular abnormalities. One can occasionally show bidirectional filling of these anastomoses depending on the vessel injected. Visualization of these anastomoses occurs to a variable degree and is sometimes entirely technique-dependent, reflecting a transient increase in the intraluminal pressure during the injection of contrast medium. - Thus, demonstration of extracranial collateral arterial flow during cerebral angiography should not necessarily be interpreted as an abnormal phenomenon, such as may be seen. with arterial occlusive disease, vascular malformation, or $a_{4}$ very vascular tumor.

Quelques particularites techniques de la circulation collatérale au cours de l'angiographie cérébrale

Résumé. Au cours de l'angiographie cérébrale par cathétérismes sélectifs par voie fémorale, peuvent apparaître des anastomoses entre des branches carotidiennes externes et l'artère vertébrale, entre l'artère vertébrale et les artères cérébrales profondes ou ascendantes et entre l'artère méningée moyenne et l'artère ophtalmique. Occasionnellement, on peut mettre en évidence un remplis- sage bidirectionnel de ces anastomoses, en rapport avec le vaisseau injecté. La visualisation de ces anastomoses se produit de facon variable dépend parfois entièrement de la technique, reflétant une augmentation transitoire de la pression dans l'artère durant l'injection du produit de contraste. Par conséquent, l'observation d'une eirculation artérielle collatérale extracrânienne pendant une angiographie cérébrale ne représente pas nécéssairement un phénomène anormal tel qu'on le rencontre dans les troubles artériels occlusifs, dans les malformations vasculaires et dans les tumeurs vascularisées.

Einige technische Besonderheiten des kollateralen Blutdurchflusses während der cerebralen Angiographie

Zusammenfassung. Während der selektiven transfemoralen Katheter-Angiographie können sich Anastomosen zwischen Externa-Gefäßen und der A. vertebralis, zwischen der $A$. vertebralis und tiefen oder aufsteigenden cervicalen Arterien und zwischen der A. meningica media und der A. ophthalmica darstellen. Diese Befunde finden sich auch bei Patienten, bei denen keine Gefäßanomalien vorliegen. Gelegentlich wird ein bidirektionaler Kontrastmitteldurchfluß durch diese Anastomosen nachgewiesen, dabei ist die Kontrastmittelfüllung von dor Lokalisation der Kontrastmittelinjektion abhängig. Es zeig't sich also, daß diese unterschiedlichen Durchströmungen technisch bedingt werden können und nicht immer als abnormales Phänomen gedeutet werden können.

\section{Introduction}

The presence of anastomoses between the external carotid and vertebral arteries, between the vertebral and ascending and deep cervical arteries, and between the middle meningeal and ophthalmic arteries is well known. Such communications are best demonstrated angiographically when they serve as collateral channels in patients with vascular occlusive disease or vascular malformations $[4,6,19,22,28]$.

In our experience, by performing cerebral angiography routinely by selective catheterization, we have shown these anastomoses fairly frequently in patients with no known vascular abnormalities. Visualization of these anastomoses is to a large degree a function of the technique of the examination.

\section{Occipital-Vertebral Anastomosis}

An anastomosis between the occipital branch of the external carotid artery and the vertebral artery was

* Presented in part at Tenth Annual Meeting of The American Society of Neuroradiology, Mexico City, Mexico, February 21-24, 1972. During part of this investigation, J.F. Seeger was a NINDS Special Fellow No. 2 F11 NS 2365-02 and R. E. Latchaw was a NINDS Special Fellow No. 1 F11 NS 02476-01.

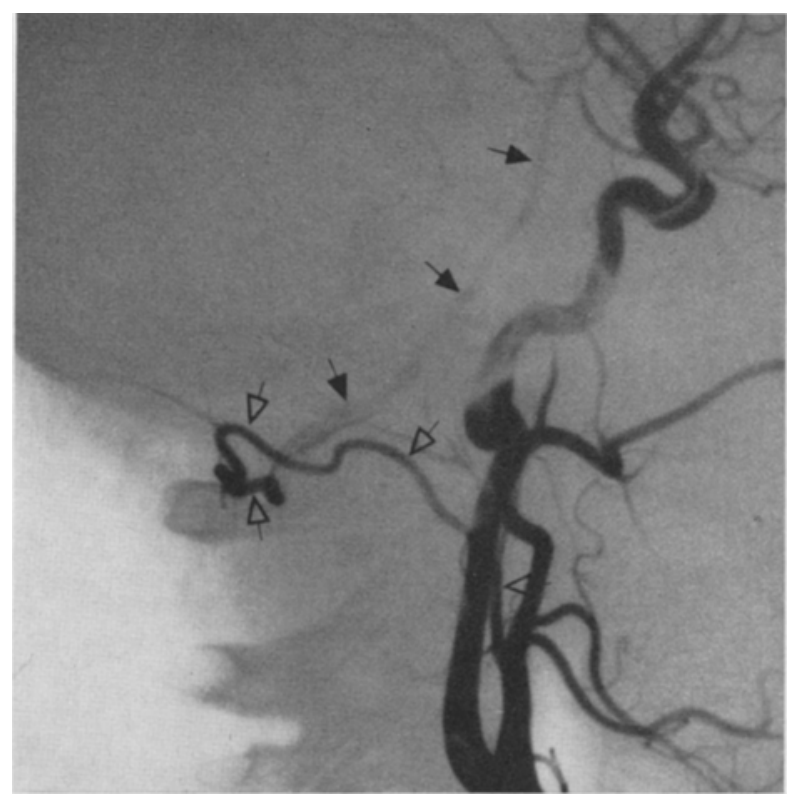

Fig. 1. 6 year old girl with histiocytoma of right orbit. Lateral projection of right common carotid angiogram. shows opacification of vertebral and basilar arteries (solid arrows) via prominent anastomosis with occipital artery (open arrows) 
present in all of 53 cadavers studied by Schulze and Sauerbrey [23] and usua!ly occurred at or near the superior surface of the posterior arch of the atlas. According to Gray [8], this communication is between the deep portion of the descending branch of the occipital artery and muscular branches of the vertebral artery.

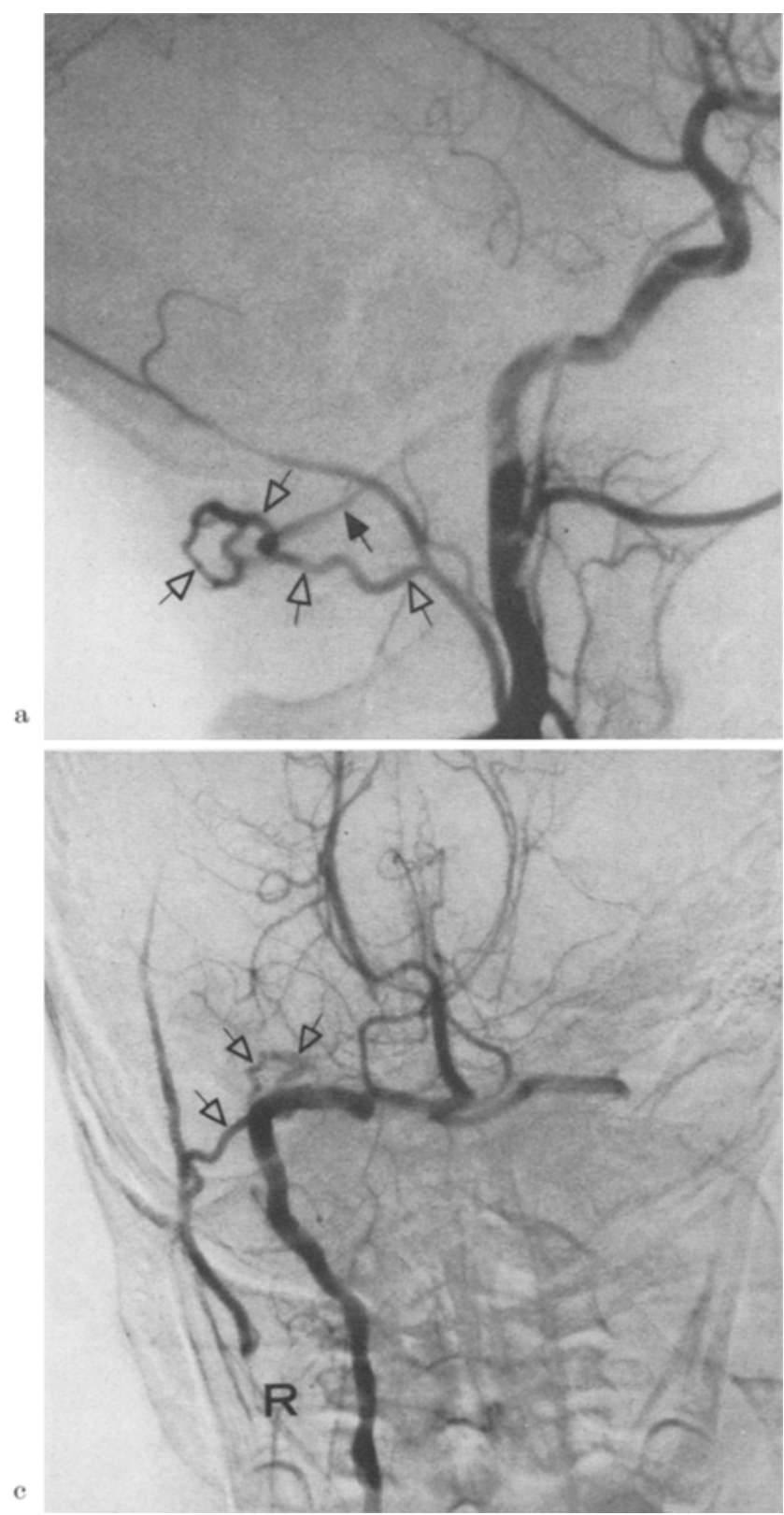

Rare reports have appeared in the literature showing opacification of this anastomosis in patients without known vascular disease, either due to inadvertent introduction of contrast medium directly into the occipital artery [22] or deliberate or accidental external carotid angiography $[2,24]$. If the anastomosis is large, in some cases perhaps representing a congenital anomaly, we occasionally have seen opacification of the vertebral artery even during common carotid angiography (Fig. 1).

Opacification of the occipital artery has also been shown during vertebral angiography [20]. Richter [19] mentioned that the occipital artery was opacified in one of his 30 vertebral angiographies performed by

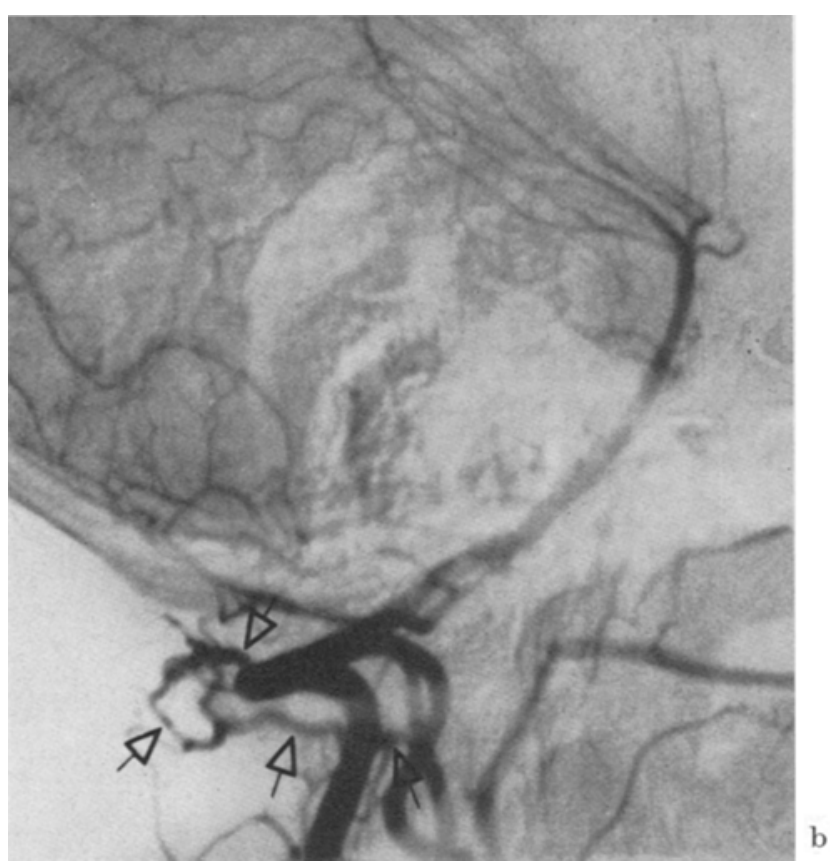

Fig. 2. 6 year old boy with brain stem glioma. a) Lateral projection of right common carotid angiogram demonstrates occipital (open arrows) to vertebral (solid arrow) anastomosis. b) Lateral and c) frontal projections of right vertebral angiogram show reverse filling of this same anastomosis (open arrows), with subsequent opacification of external carotid artery branches

percutaneous puncture. With selective catheterization, the vertebral to occipital anastomosis may be seen quite frequently during vertebral angiography even in patients who have no associated carotid occlusive disease, vascular malformation or congenital anomaly. Occasionally, bidirectional filling of this anastomosis can be demonstrated during selective carotid and verteberal angiographies (Fig. 2). 
This normal anastomosis should not be confused with various congenital anomalies such as a primitive hypoglossal artery or proatlantal intersegmental artery [26], nor should visualization of this anastomosis during common carotid angiography necessarily imply hypoplasia or absence of the ipsilateral vertebral artery (Fig. 2).

\section{Ascending Pharyngeal-Vertebral Anastomosis}

Another anastomosis between the external carotid and vertebral arteries which rarely has been illustrated

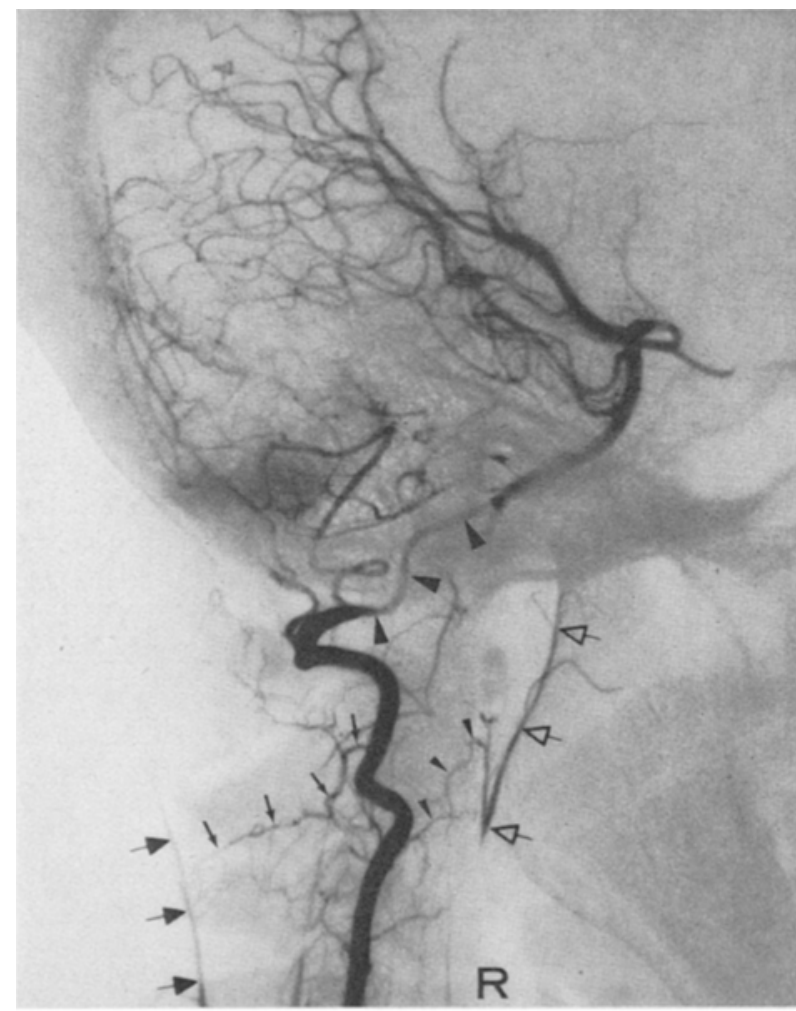

a tive external or common carotid angiographies but have occasionally visualized the ascending pharyngeal artery during selective vertebral angiographies (Figs. $3,4)$. Although we have not found it illustrated in textbooks of anatomy, the anastomosis between the ascending pharyngeal artery and the vertebral artery in all our cases occurred anterior to the vertebral artery and inferior to the level of the vertebral-occipital anastomosis, presumably between muscular branches of the vertebral artery and prevertebral branches of the ascending pharyngeal artery [8, 18]. This localization

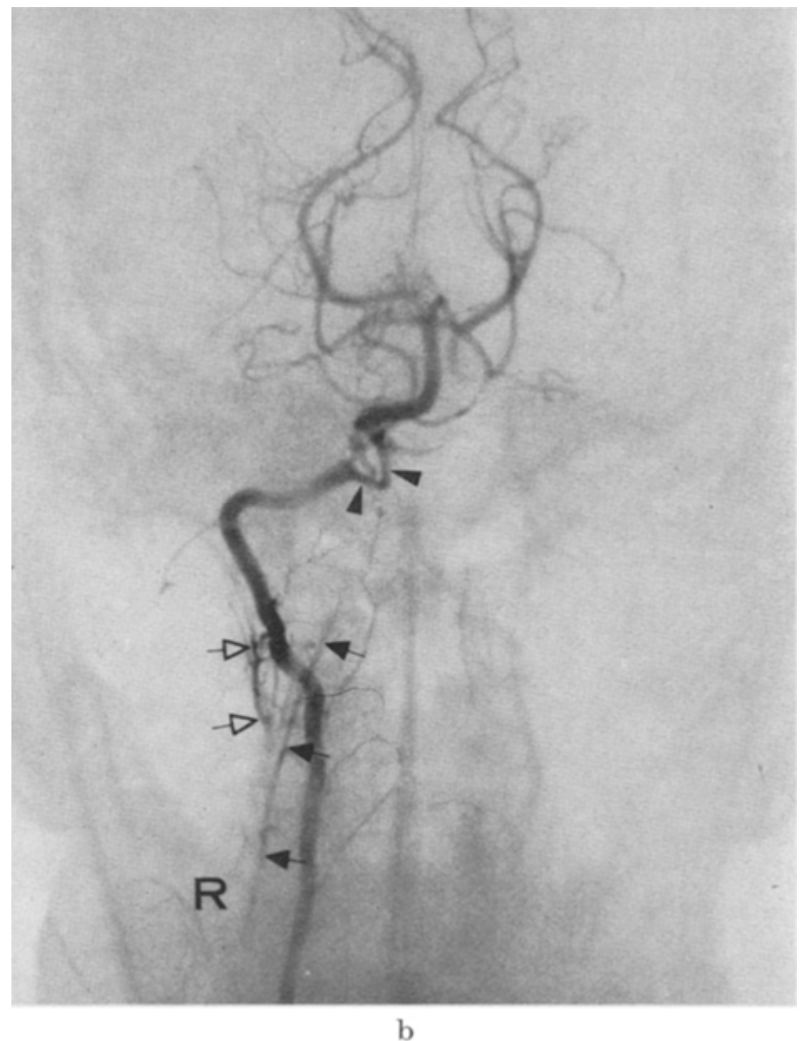

Fig. 3. 30 year old woman with diplopia and left periorbital pain. Right vertebral angiogram. a) Lateral projection shows ascending pharyngeal artery (open arrows) opacified by collaterals (small arrowheads) from vertebral artery. Collaterals (small arrows) to deep cervical artery (large solid arrows) are also demonstrated. b) Frontal projection shows ascending pharyngeal (open arrows) and deep cervical (solid arrows) arteries. Note congenital hypoplasia of right vertebral artery (large arrowheads) beyond origin of posterior inferior cerebellar artery in a) and b)

angiographically involves the ascending pharyngeal artery. Wiedenmann [29] reported a case of inadvertent placement of a needle into the ascending pharyngeal artery with opacification of a communication with the vertebral artery during injection of $5 \mathrm{ml}$ of contrast material. We have seen one such case with unintentional catheterization of the ascending pharyngeal artery during attempted external carotid angiography. Another example of this anastomosis was shown by Nierling et al., [16] during common carotid angiography in a patient with occlusion of the internal carotid artery. In patients without vascular abnormalities, we have not seen this anastomosis during selec- is in agreement with the illustrations in the two previous case reports $[16,29]$.

It is interesting to note that an occasional patient will complain of a burning sensation in the back of the throat during selective vertebral angiography. This is presumably caused by contrast material entering the ascending pharyngeal artery through vertebral anastomoses.

\section{Vertebral-Ascending and/or -Deep Cervical Anastomoses}

The ascending and deep cervical arteries anastomose with each other, with the vertebral artery, and with the occipital artery [18]. The ascending cervical 
artery, lying somewhat more superficial and anterior than the deep cervical artery, also communicates with the ascending pharyngeal artery $[8,18]$. We occasionally observe opacification of either the ascending or deep cervical artery during selective vertebral angiography, more commonly the latter (Figs. 3, 4, 5).

\section{Middle Meningeal-Ophthalmic Anastomosis}

An anastomosis between the middle meningeal artery and the lacrimal branch of the ophthalmic artery passes through the superior orbital fissure. This communication was constantly seen (although variable in size) in 170 anatomical specimens studied by Hayreh [10]. It is most commonly demonstrated angiographically when it serves as a collateral in patients with stenosis or occlusion of either the internal or external carotid artery.

Several previous angiographic reports have described an anomalous origin of the middle meningeal from the ophthalmic artery $[3,7,25]$, or an anomalous origin of the ophthalmic from the middle meningeal artery [5]. Such anomalies certainly seem to occur $[9$,

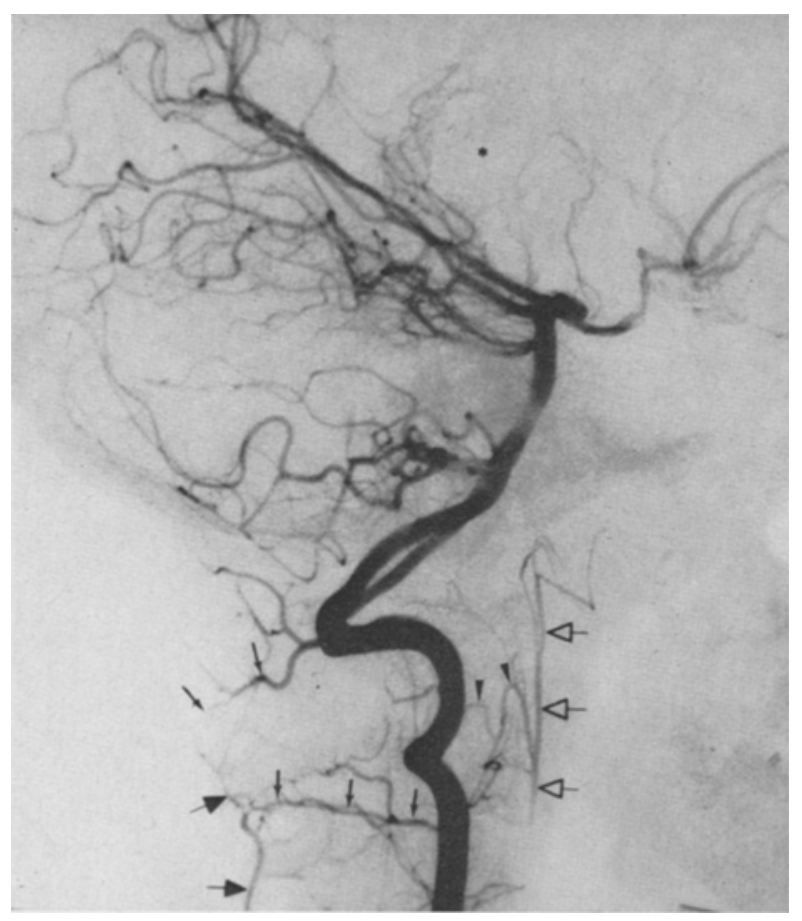

Fig. 4. 12 year old boy with papilledema and early hydrocephalus from small tumor in the pineal region (*). Lateral projection of left vertebral angiogram. Opacification of ascending pharyngeal (open arrows) and deep cervical (solid arrows) arteries as in Fig. 3

10]. However, most of the angiographically illustrated cases were either common, internal, or external carotid angiographies, but not selective injections into the internal carotid artery and the external carotid artery. Demonstration of an apparent anomaly during either internal or external carotid angiography may in fact be a reflection of a normal but prominent anastomosis [13]. The true situation often becomes obvious if both vessels are studied selectively in the same patient (Fig. 6).

\section{Discussion}

Despite some reports to the contrary $[1,11]$, there is little doubt that a definite, though probably slight, increase in intraluminal pressure occurs during injection of contrast material into either the carotid or vertebral artery. This is perhaps best illustrated by the fairly frequent finding of reflux from the anterior communicating artery into the vascular bed of the opposite carotid artery during selective internal carotid angiography or reflux into the opposite vertebral artery during selective vertebral angiography. Saltzman [21] found a much higher incidence of opacification of the posterior cerebral artery during internal than common carotid angiography. Lodin and Ottander [15] reported a higher incidence of spontaneous flow through the anterior communicating artery following internal than common carotid artery puncture and also with automatic pressure as opposed to manual injection of contrast material. It seems obvious that such patterns of flow can occur only from a higher to a slightly lower pressure area. We feel that this transient increase in intravascular pressure, at least early during the injection, is, in most instances, responsible for "techniquedependent" opacification of the previously described anastomoses. This opinion is supported by the intraarterial pressure recordings which Lin et al., [14] obtained in the brachial and carotid arteries during retrograde brachial angiography.

Numerous variables will, of course, affect the head of pressure during injection of contrast material. The catheter may cause partial obstruction when placed in a small vessel and spasm associated with catheter placement may contribute to the obstruction. A relatively generous bolus of contrast material will then flood the small vascular bed and may "overflow" into existing anastomoses which are usually not visualized. It follows that the more selective the catheterization, the greater is the likelihood of demonstrating these anastomoses. This is true even with no apparent compromise of the vessel lumen by either the catheter alone or catheter plus spasm.

The rate of injection of contrast material also influences opacification of these anastomoses. Our standard technique in adults and older children is to deliver, with a pressure injector over a one second period, $8 \mathrm{ml}$ of meglumine iothalamate $60 \%$ (Conray) with common carotid, $7 \mathrm{ml}$ with internal carotid and $5-6 \mathrm{ml}$ with selective vertebral angiographies. With external carotid angiography, $3-5 \mathrm{ml}$ of contrast is usually hand injected. Proportionately less contrast material is used for cerebral angiography in infants and young children. 

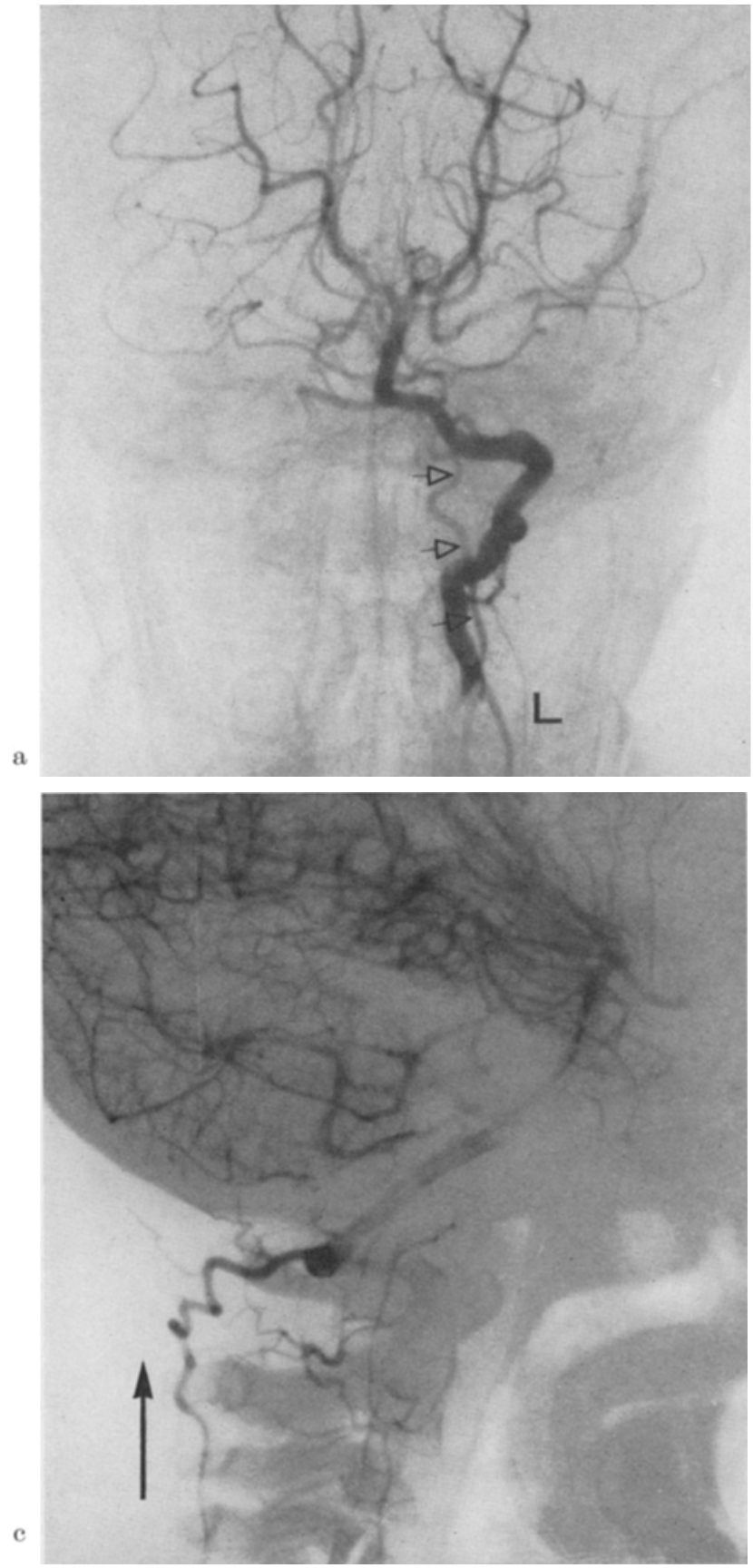

Any process which increases the peripheral resistance to flow or decreases the size of the peripheral vascular bed tends to enhance the transient elevation of pressure in an injected vessel and thus should lead to a greater frequency of opacification of available anastomoses. In our experience, there is a particularly high incidence of opacification of these collaterals in patients who have increased intracranial pressure from any cause (Fig. 4) or intracranial arterial spasm. One patient in whom the vertebral-ascending pharyngeal and vertebral-deep cervical anastomoses were de-

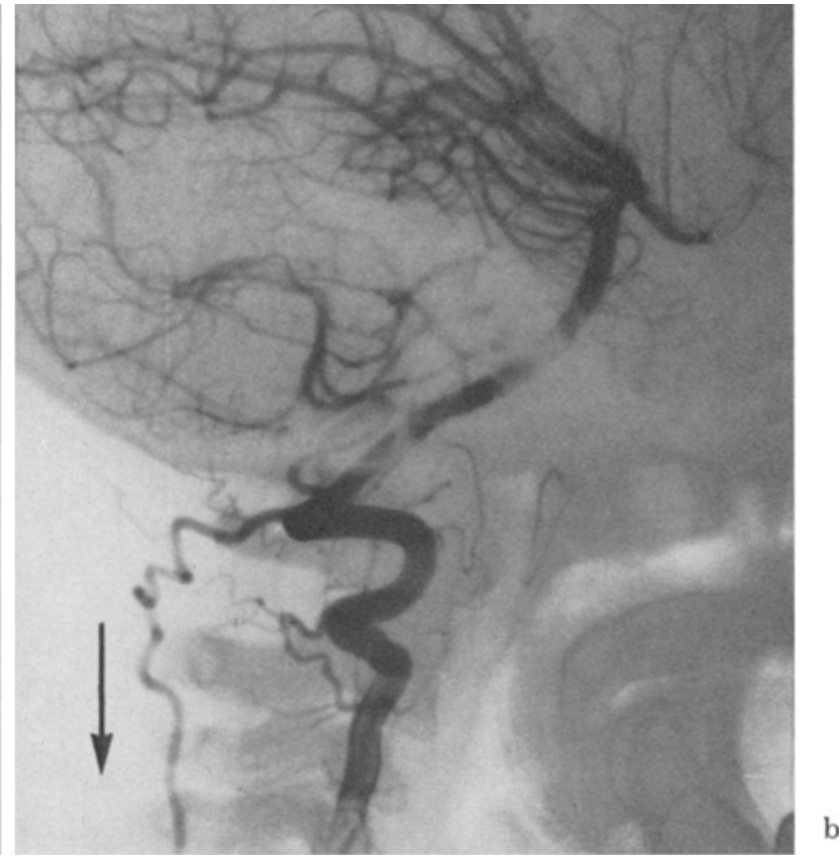

Fig. 5. 6 year old girl with right temporal epidural hematoma. a) Frontal and b) and c) lateral projections of left vertebral angiogram. Prominent anastomosis between vertebral artery and deep cervical artery (open arrows) with retrograde filling of the latter $(\downarrow)$ on early film and antegrade clearing from below ( $\uparrow) 3 / 4$ sec later

monstrated during vertebral angiography, had a congenitally hypoplastic vertebral artery between the orgin of the posterior inferior cerebellar artery and the basilar artery (Fig. 3), which presumably offered an increased resistance to flow of contrast material similar to that which may occur with peripheral arterial spasm.

We have also noted that these anastomoses are seen more frequently in children than in adults. Visualization depends to some extent on the size of the anastomoses, which can vary from minute communications to what some might consider congenital anom- 

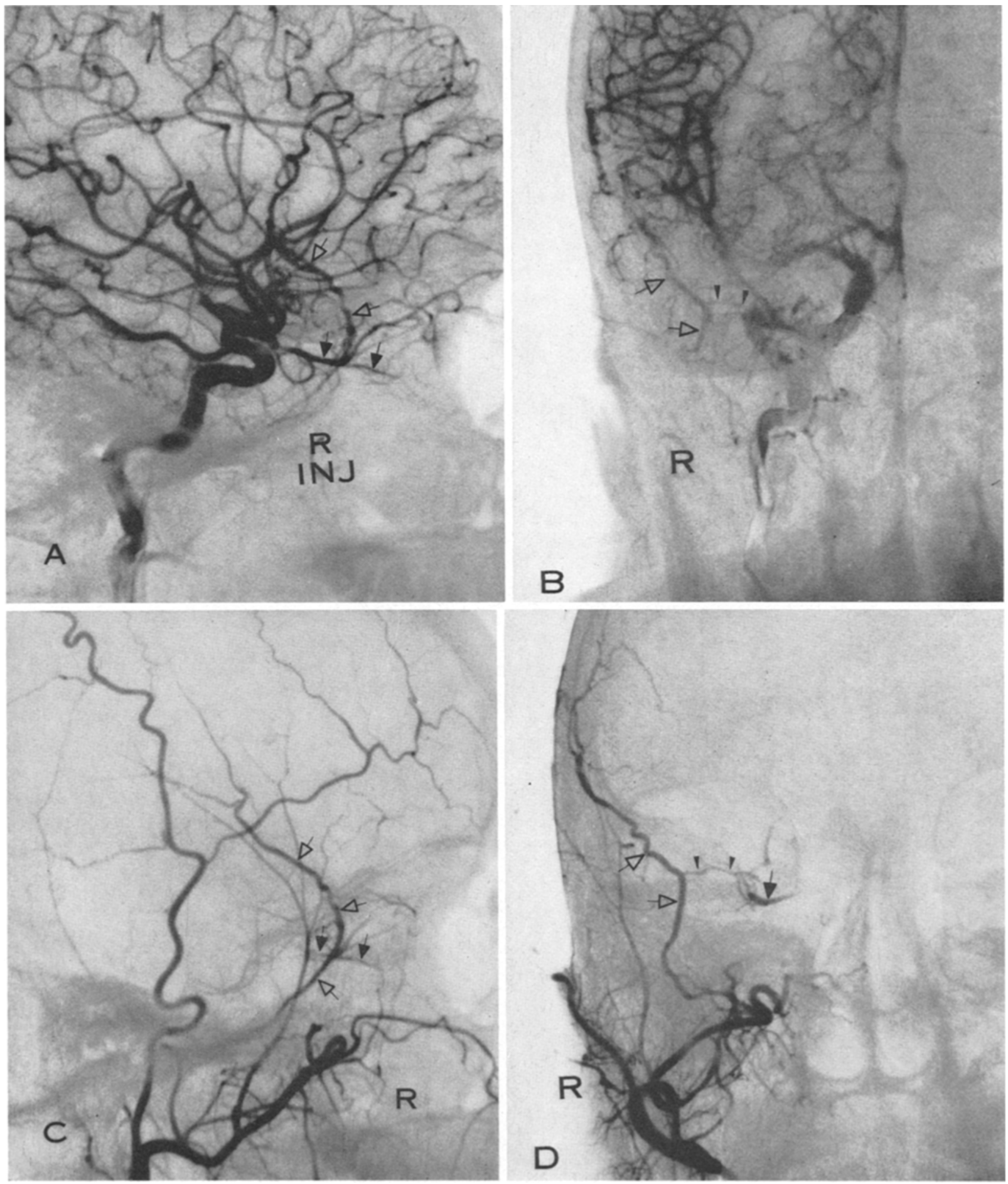

Fig, 6. 25 year old woman with papilledema. a) Lateral and b) frontal projections of right internal carotid angiogram show opacification of anterior branch of middle meningeal artery (open arrows) via anastomosis (arrowheads) with ophthalmic artery (solid arrows). c) Lateral and d) frontal projections of right external carotid angiogram show reverse direction of flow through same anastomosis (arrowheads) with opacification of ophthalmic artery (solid arrows) from middle meningeal artery (open arrows) 
alies. It is reasonable to assume that many of the communications between the carotid and vertebrobasilar systems, which are prominent during embryological development [17], would tend to be larger in infants and children than in adults, in the absence of vascular occlusive disease.

Some patients, especially children who are studied without anesthesia, may hyperventilate to a variable degree because of anxiety. Hyperventilation leads to decreased arterial $\mathrm{pCO}_{2}$ and increased intracranial vascular resistance [12], which, in turn, probably leads to a higher incidence of opacification of available extracranial anastomoses. Similar changes may occur secondary to various drugs and anesthetics.

Ketamine is frequently employed at our institution during angiographic procedures in children. This drug causes and increase in cerebral blood flow [27]. Although at first glance appearing somewhat paradoxical, such increased flow may also in part lead to a greater degree of opacification of available collaterals, since any increase in cerebral blood flow due to dilatation of the cerebrovascular bed would cause an increase in intracranial volume and elevation of intracranial pressure.

\section{References}

1. Bakay, L., Sweet, W.H.: Cervical and intracranial intra-arterial pressures with and without vascular occlusion. Surg. Gynec. Obstet. 95, 67-75 (1962)

2. Barnett, H.J.M., Wortzman, G., Gladstone, R.M., Lougheed, W.M.: Diversion and reversal of cerebral blood flow. Neurology 20, 1-14 (1970)

3. Bernasconi, V.: Abnormal origin of the middle meningeal artery from the ophthalmic artery. Neurochirurgia (Stuttg.) 8, $81-85$ (1965)

4. Bosniak, M. A. : Cervical arterial pathways associated with brachiocephalic occlusive disease. Amer. J. Roentgenol. 91, 1232-1244 (1964)

5. Brucher, J.: Origin of the ophthalmic artery from the middle meningeal artery. Radiology 93, 51-52 (1969)

6. Chou, S.N., Story, J.L., Seljeskog, E., French, L.A.: Further experience with arteriovenous fistulas of the vertebral artery in the neck. Surgery 62, 779 $\rightarrow 788$ (1967)

7. Gabriele, O.F., Bell, D.: Ophthalmic origin of the middle meningeal artery. Radiology $\mathbf{8 9}, 841$-844 (1967)

8. Gray, H.: Anatomy of the human body, pp. 583-614. Philadelphia: Lea and Febiger 1966

9. Harvey, J.C., Howard, L. M.: A rare type of anomalous ophthalmic artery in a negro. Anat. Rec. 92, 87$90(1945)$

10. Hayreh, S. S. : Arteries of the orbit in the human being. Brit. J. Surg. 50, $938-953$ (1963)

11. Hilal, S.K.: Hemodynamic changes associated with the intraarterial injection of contrast media. Radio$\log y 86,615-633$ (1966)

12. Huber, P., Handa, J.J.: Effect of contrast material, hypercapnia, hyperventilation, hypotonic glucose and papaverine on the diameter of cerebral arteries. Invest. Radiol. 2, 17-32 (1967)

13. Kuru, Y.: Meningeal branches of the ophthalmic artery. Acta radiol. (Diagn.) 6, 241-251 (1967)

14. Lin, J.P., Kricheff, I.I., Chase, N.E.: Blood pressure changes during retrograde brachial angiography. Radiology 83, 640-646 (1964)

15. Lodin, H., Ottander, H.: The eirculation through the anterior communicating cerebral artery on automatic contrast injection. Clin. Radiol. 18, 268-271 (1967)

16. Nierling, D.A., Wollschlaeger, P.B., Wollschlaeger, G.: Ascending pharyngeal-vertebral anastomosis. Amer. J. Roentgenol. 98, 599-601 (1966)

17. Padget, D.H.: The development of the cranial arteries in the human embryo. Contr. Embryol. Carneg. Instn. 32, 205-261 (1948)

18. Piersol, G.A.: Human anatomy, p. 739, 746. Philadelphia: J.B. Lippincott 1930

19. Richter, H.R.: Collaterals between the external carotid artery and the vertebral artery in cases of thrombosis of the internal carotid artery. Acta Radiol. 40, 108-112 (1953)

20. Rossi, P., Rosenbaum, A., Zingesser, L.: The fate of the carotid artery after occlusion for treatment of aneurysm. Radiology 95, 567-575 (1970)

21. Saltzman, G.F.: Angiographic demonstration of the posterior communicating artery and posterior cerebral arteries. I. Normal angiography. Acta Radiol. 52, $1-20(1959)$

22. Schechter, M. M.: The occipital-vertebral anastomosis. J. Neurosurg. 21, 758-762 (1964)

23. Schulze, H.A.F., Sauerbrey, A.: Zur Frage der Anastomosen zwischen der A. vertebralis und der A. occipitalis. Zbl. Neurochir. 16, 76-80 (1956)

24. Schürmann, K.: Darstellung der A. vertebrolis und ihrer Äste in Angiogramm von der A. carotis externa aus. Zbl. Neurochir. 14, 362-365 (1954)

25. Stattin, S.: Meningeal vessels of the internal carotid artery and their angiographic significance. Acta Radiol. 55, 329-336 (1961)

26. Sutton, D.: The vertebro-basilar system and its vascular lesions. Clin. Radiol. 22, 271-287 (1971)

27. Takeshita, H., Okuda, Y., Sari, A.: The effects of ketamine on cerebral circulation and metabolism in man. Anesthesiology 36, 69-75 (1972)

28. Weibel, J., Fields, W.S.: Atlas of Arteriography in Occlusive Cerebro-vascular Disease. Philadelphia: W. B. Saunders Co. 1969

29. Wiedenmann, O.: Eine extrakranielle Anastomose zwischen dem Versorgungsgebiet der A. carotis externa und der $A$. vertebralis. Fortschr. Roentgenstr. 96, 201-203 (1962)

Joachim F. Seeger, M.D.

Department of Radiology

University of Michigan Medical Center

Ann Arbor, Michigan 48104

U.S.A. 